\title{
POPPER: UNA LECTURA ESCÉPTICA
}

\author{
Isidoro REGUERA \\ Universidad de Extremadura
}

Resumen: En la teoria del conocimiento popperiana a partir de la mitad de los años sesenta en que comienza a hablar de los tres mundos - la única que nos interesa en este artículo- no hay otra historia que la de la ameba laboriosa y evolucionada, que somos, en su proceso de supervivencia, de adaptación al mundo, sin mayores recursos que los de un apriori biológico y una evolución cultural fundados en la ley generalisima del ensayolerror, que mueve tanto la selección natural darwiniana como la preferencia racional de Popper. De modo que toda la cuestión cognoscitiva se reduce a lo siguiente: tentativas (animosas) de adaptación al medio, conjeturas (audaces) derivadas de ellas y memoria (genética) de los ensayos exitosos...

Estas líneas generales dan la medida del racionalismo popperiano, de pocos vuelos, que no pinta un cuadro muy halagüeño, que digamos, para el conocimiento ni para su teoría. La teoría del conocimiento es teoría del aumento del conocimiento y el conocimiento mismo es un proceso siempre inacabado, siempre crítico, en pos de una verdad que no es más que verosimilitud y que no le pertenece más de lo que le pertenece el error. El conocimiento se agota en esa tensión hacia la grisura; y su teoría, en la de su evolución zoológica.

Sobre estas bases es fácil hacerse ya una idea del talante escéptico moderado del vienés. Su escepticismo será más bien una rebelión general contra el dogmatismo. Y contra el fundamentalismo y el subjetivismo, en particular, de la epistemología tradicional que él llama "del cubo": la que busca desde Descartes a toda costa la seguridad consoladora de la certeza de nuestros juicios, cosa que a Popper le parece absolutamente irrelevante puesto que en el mejor de los casos no dejaría 
de ser una certeza psicológica, típica de los productos epistemológicamente banales del mundo dos. La crítica incesante de Popper a esta epistemología tradicional moderna, frente a la que la suya asume la conjetura y la hipótesis, la amenaza de error, el cambio, la perpetua inseguridad, el perpetuo ensayo, etc. como categorías esenciales del conocimiento, ofrece una apariencia de escepticismo de mayor calado del que realmente tiene: un escepticismo dinámico, porque impulsa al conocimiento a no dormirse en falsas seguridades dogmáticas, y esperanzador, por esa misma tensión racional crítica hacia la verdad que convierte a ésta en su propia búsqueda y la vida del intelectual, en un camino en esa dirección en el tercer mundo. Un escepticismo light, posmoderno, consciente y confeso por demás, el de Popper, que gira en torno a su teoría del conocimiento y de la verdad, como es lógico, y desde ellas adquiere sus matices. Veamos.

\section{Epistemologia objetiva y evolucionista}

Dicho de otro modo: el escepticismo de Popper coincide con su lucha por la objetividad; o con su lucha contra el subjetivismo; y esas luchas son toda una aventura evolutiva... La objetividad es el concepto más característico, en general, del pensamiento popperiano. Su búsqueda describe todo el pensamiento del vienés. La cuestión fundamental de la teoría del conocimiento (o epistemología) popperiana es la de la clarificación e investigación objetivas del proceso objetivo de aumento objetivo del conocimiento objetivo. Un conocimiento sin sujeto y por lo tanto sin la posibilidad de ninguno de sus supuestos amparos frente al escepticismo.

\section{Base animal e insegura del conocimiento}

¿Cómo comienza y funciona esa objetividad y evolución del conocimiento? Comienzan y funcionan sin alarde alguno, sin plantear la cuestión en otros cauces que no sean los zoológicos, en la conciencia de que no somos más que la ameba o la bacteria primitiva evolucionada que aún perdura en cada uno de nosotros. El proceso del conocimiento ha sido y es una evolución genética desde ellas hasta la capacidad crítica objetiva del hombre, que sigue basándose y dependiendo de su condición biológica, reducto de todo apriori: la memoria genética de los lances exitosos en la simplísima dialéctica animal del ensayo/error con el medio. Más a ras de suelo no pueden situarse los planteamientos. El hecho de 
que el animal también conoce es el hecho básico de la teoría del conocimiento que la ha revolucionado (MP 58ss.) ${ }^{1}$. Recurrir a teorías biológicas para explicar nuestra observación y percepción se muestra más efectivo que ningún tipo de dogmatismo metafísico y confuso sobre el conocimiento directo, inmediato o intuitivo. Frente a las excelencias modernas en la adoración del conocimiento y de la subjetividad creadora no extraña que todo este prosaísmo resulte de tintes escépticos. Y de hecho el escepticismo popperiano no es más -de raíz- que eso.

Toda ciencia y toda filosofía son "sentido común ilustrado" (CO 42) o, si lo queremos más preciso, sentido común «bacteriano» ilustrado (MP 89). El conocimiento surge del propio sentido común que ilustra y esa ilustración, además, es toda su tarea. El sentido común son los automatismos inconscientes heredados - y evolucionados - de la ameba. Lo es así subjetiva e intersubjetiva, individual y socialmente: intersubjetiva y socialmente es la opinión común; subjetiva o individual, es decir primordialmente, radica en una confusa comunidad de mis sentidos. Estos son las fuentes primordiales de conocimiento, los accesos universales a la mente: da igual que ésta esté más o menos vacía o llena, lo importante es que aprendemos la mayoría de las cosas, o todas, por la penetración de la experiencia a través de los sentidos (CO 66). Toda experiencia, pues, consta de información recibida a través de ellos; otra cosa es si esta incursión resulta inmediata y clara... y si el territorio irrumpido es virgen o no... Desde luego que no: el apriori genético se encarga de mediatizar la incursión y mancillar el terreno, pero por ahora quedémonos con que al igual que los sentidos el sentido común, como inexcusable punto de partida del

1 Siglas utilizadas al citar en este artículo:

CO: Conocimiento objetivo. Un enfoque evolucionista (1972), Tecnos, Madrid, 1974.

C\&R: EL desarrollo del conocimiento cientifico. Conjeturas y refutaciones (1967), Paidós, Buenos Aires, 1967.

EPEE: "Die erkenntnistheoretische Position der Evolutionären Erkenntnistheorie», en: Riedl, R. \& Wuketits, F. M. (eds.): Die Evolutionäre Erkenntnistheorie, Paul Parey, Berlin \& Hamburg, 1987, 29-40.

LIC: La logica de la investigación cientifica (1934), Tecnos, Madrid, 1977.

MP: Un mundo de propensiones (1990), Tecnos, Madrid, 1992.

OU: The Open Universe. An Argument for indeterminism, Hutchinson, London, 1982. (Trad. cast.: El universo abierto: Un argumento en favor del indeterminismo, Tecnos, Madrid, 1984.)

SBW: Auf der Suche nach einer besseren Welt. Vorträge und Aufsätze aus dreissig Jahren, Piper, München \& Zürich, 1984. 
conocimiento, no es nada seguro. Con ese término vago de "sentido común» hacemos referencia a algo impreciso y cambiante como «los instintos u opiniones de la gente», sean adecuados o no.

¿Cómo es posible que algo tan vago e incierto sea el punto de partida de un conocimiento que se quiere científico, objetivo y verdadero? Hoy ya no tenemos la manía fundamentalista de la Modernidad, no pretendemos construir un sistema seguro sobre fundamentos ciertos - como Descartes, Spinoza, Locke, Berkeley o Kant-, entre otras cosas porque sabemos por la experiencia frustrada de éstos que se trata de una empresa vana y que por tanto su planteamiento es absurdo, sin sentido. (Lo que no tiene respuesta o solución no es pregunta ni problema alguno.) De modo que la realidad se impone y la ciencia, la objetividad y verdad del conocimiento han de construirse sobre bases humildes como éstas: zoología y sentido común. Para Popper, la inseguridad que esto produce y la crítica subsecuente que permite actúan más bien como motor y acicate del conocimiento. Esa es también la consciencia posmoderna. Y a la consciencia de esa precariedad es a lo que alguien hoy desde presupuestos dogmáticos podría llamar en sentido fuerte y como una invectiva escepticismo. Pero no es más que una conciencia clara y económica frente a las muchas ilusiones vanas, luego frustradas de «las luces». Escepticismo sólo en este sentido.

\section{Aumento frente a fundamento}

Si asumimos esta base vaga e insegura del conocimiento cualquier intento fundamentalista resulta extravagante. Desde la Lógica de la investigación cientifica Popper no buscó nunca fundamento ni justificación alguna últimos para el conocimiento ${ }^{2}$. Es en este sentido en el que plantea el problema del conocimiento simplemente como la cuestión de su aumento, que cree poder analizar modélicamente en el estudio del conocimiento científico. Eso es todo. No cae en las trampas del círculo epistemológico de la Modernidad de pensar la propia posibilidad y condiciones del pensar sin salir nunca de ese agujero esencialista y fundamentalista. Crecimiento del conocimiento, conocimiento

2 Cfr. P. MARKL, "Evolutionäre Erkenntnistheorie bei Karl Popper», en: R. Riedl \& E. M. Bonet (eds.), Entwicklung der evolutionären Erkenntnistheorie, Edition S, Viena, 1987, 35-45, 35-36. 
nuevo, revolucionario y conjetural: ésos fueron los únicos intereses epistemológicos de Popper desde siempre (EPEE 40). Frente a los filósofos fundamentalistas de la creencia y certeza Popper considera que todas nuestras conjeturas de sentido común pueden ser criticadas, rechazadas y cambiadas por otras si la crítica tiene éxito, como sucedió por ejemplo con las hipótesis de la tierra plana o del geocentrismo. La crítica es el motor del aumento de conocimiento, decíamos, y pergeña así todo un ideal racionalista crítico. "Comenzamos con un punto de partida vago y construimos sobre una base insegura. Con todo podemos progresar: algunas veces, tras una crítica, podemos ver que nos hemos equivocado; podemos aprender de nuestros errores... Mi primera tesis es que partimos del sentido común, siendo la crítica nuestro gran instrumento de progreso" (CO 42). Zoología, sentido común y crítica son, pues, las bases -inseguras- del conocimiento y de su aumento. Corrigiendo y desmenuzando la vaguedad del punto de partida va destapándose poco a poco el «universo abierto" de Popper hacia un ideal evolutivo no violento.

\section{Mediación biológica frente a inmediatez pura}

¿Por qué no le parecen oportunas a Popper como punto de partida o fundamento del conocimiento todas esas experiencias subjetivas propias, esas certezas y creencias sentidas como particularmente fuertes y seguras, y no sólo para Descartes, Locke o Berkeley sino también para el «escéptico» Hume, que pertenecen tanto a los sentidos como al sentido común, como insinuábamos, punto de partida o base aceptada de nuestro conocimiento? Porque se insiste no en su vaguedad e inseguridad sino en su inmediatez, claridad y distinción y en el enrasamiento y vacío de la mente que las recibe. Todo en la epistemología de la tabula rasa o del cubo resulta muy ingenuo y por ello muy equivocado. Se supone que no hay mediación alguna entre los aportes de nuestra experiencia y la mente y por ello tampoco ninguna vaguedad ni inseguridad a la base del conocimiento. El baluarte de cualquier escepticismo es siempre la ilusión de pureza. Pero, por el contrario, Popper se esfuerza en demostrar el hecho y espesor de una mediación biológica obvia, una serie de procesos intermediarios semejantes a los de cualquier organismo en su interacción con el medio.

"Aprender a descifrar los mensajes que nos llegan es algo extremadamente complicado que se basa en disposiciones innatas. Mi conjetura es que tenemos una dis- 
posición innata a referir los mensajes a un sistema coherente y en parte regular $\mathbf{u}$ ordenado: la "realidad". En otras palabras, nuestro conocimiento subjetivo de la realidad se compone de disposiciones innatas que van madurando... Sea lo que sea, aprendemos a descifrar por ensayo y supresión de errores y, aunque logremos una gran precisión y rapidez para experimentar el mensaje descifrado como si fuese "inmediato" o "dado", siempre aparecen algunos errores, corregidos normalmente mediante mecanismos especiales de gran complejidad y considerable eficaciam ${ }^{3}$.

No hay nada directo o inmediato en nuestra experiencia. Siempre hay ya que "descifrarla" o "interpretarla". Lo que sucede es que aprendemos tan bien a hacerlo por un entrenamiento repetido (como tocar el piano o conducir un coche) que todo se nos vuelve aparentemente muy directo e inmediato, apariencia que la produce sólo el aprendizaje maquinal. (La "custom» humeana...) Aún en los casos de la experiencia aparentemente más simple y directa está trabajando todo un aparato descodificador o todo un complicado proceso de descodificación, como dice Popper. Aún con todo bien repetido y aprendido se cometen faltas; nada garantiza una certeza absoluta, ni siquiera esa supuesta inmediatez efectiva, aunque con la certeza relativa y corriente tengamos suficiente para la mayoría de las tareas prácticas.

Hay que abandonar, pues, la búsqueda de la certeza y de fundamentos ciertos del conocimiento. Este olvido de la certeza es escepticismo en sentido fuerte sólo para las ilusiones metafísicas modernas, presididas por ese afán que Dewey denomina el de la «búsqueda de la certeza». Búsqueda de la verdad y no de la certeza ha de ser la mira de una teoría del conocimiento objetivo como la que propugna Popper. La búsqueda de la certeza, que comporta siempre el miedo al escepticismo, se basa ciertamente en unos presupuestos muy ingenuos hoy: los de la claridad, distinción e inmediatez que ellos suponen entre una mente purísima y vacía y el mundo externo. Pero el conocimiento nunca parte de cero, como quieren las teorías «inmediatas»: siempre presupone lo que Popper llama conocimiento "básico», «apriórico», «inconsciente» o "innato" ${ }^{4}$; un "trasfondo", cuya base más general a niveles del mundo tres sería ya el lenguaje 5 , pero

3 (CO 68). La cuestión del apriorismo popperiano es de lo más interesante de su epistemología. No es lugar éste para tratarla en profundidad. Cfr. para ello, por ej., mi libro, El tercer mundo popperiano, UEX, Cáceres, 1995, 171-182.

4 Cfr. CO 74; MP 60, 67; EPEE passim.

5 Cfr. CO 157; C\&R 264. 
que a los niveles primarios consta de disposiciones y expectativas biológicas innatas, que en cualquier caso son ya instancias concienciales de adaptación a la vida y al medio. Todo ello se da por supuesto y pasa inadvertido. De modo que pueden establecerse dos cosas: (1) en cada estadio de la evolución de la vida hemos de suponer la existencia de algún conocimiento de esta forma, y (2) el aumento de conocimiento consiste en la modificación (mucha o poca) del conocimiento previo o básico en vistas a una mayor aproximación a la verdad o verosimilitud. Popper llega a decir que «el 99,9 por 100 del conocimiento de un organismo es heredado o innato" y sugiere incluso que "también es innata la plasticidad precisa para estas modificaciones $^{6}$

\section{Crítica y error}

Naturalmente éstos son los primeros pasos del conocimiento que compartimos con el animal en mucho puntos, pero tampoco su aumento a otros niveles de mundo sigue leyes de evolución muy distintas. Se trata sólo de otros niveles pero la marcha esquemática es la misma. El conocimiento realmente humano comienza cuando la selección natural crítica y consciente supera y completa en parte a la natural, que es el momento también de la aparición de las funciones superiores del lenguaje; cuando ello nos permite perseguir —crítica y conscientemente - el error y discriminar - crítica y conscientementeno sólo entre inputs orgánicos elementales sino también entre teorías mejores o peores; cuando estamos de lleno, pues, en la dialéctica (interacción) racional y crítica de los mundos ya desde la más propia y más humana del mundo tres.

"No hay conocimiento sin crítica racional, crítica al servicio de la búsqueda de la verdad. Los animales no tienen conocimiento en este sentido.

6 Cfr. CO 74; EPEE 36; MP 84. De estos mecanismos mediadores de descodificación de la experiencia o de nuestras destrezas descifradoras, precisamentepor su apariencia de inmediatez y de facilidad y por su carácter animal básicamente compartido con las demás especies en las que es universal el método de ensayo/error, hay razones definitivas para pensar, en efecto, que tienen todos una base biológica hereditaria o genética. "Toda persona que entienda algo de biología ha de tener claro el carácter innato de la mayoría de nuestras disposiciones, sea en el sentido de que hemos nacido con ellas (por ejemplo la disposición a respirar, succionar, etc.) o en el sentido de que, en el proceso de maduración, el desarrollo de la disposición se ve solicitado por el medio (por ejemplo, la disposición a aprender un lenguaje)" (CO 70). 
Naturalmente que ellos conocen muchísimas cosas -el perro conoce a su amo-. Pero aquello que llamamos conocimiento, $y$, sobre todo, el conocimiento científico, va unido a la crítica racional. Aquí está por tanto el paso decisivo, que depende de la invención de las proposiciones verdaderas o falsas. $\mathrm{Y}$ éste es el paso que, supongo, funda el mundo tres, la cultura humana» ${ }^{7}$.

La actitud de crítica racional y sistemática hacia las teorías es así el comienzo de la ciencia, del conocimiento típicamente "humano" y "objetivo", donde el error que puede mostrar la crítica cumple una función positiva también en el proceso de conocimiento. Casi podíamos decir que en el evolucionismo epistemológico popperiano vale igual la verdad o el error de las teorías porque lo importante para el aumento de conocimiento, que es lo importante en sí en el conocimiento, es la crítica racional motor de la evolución crítica (o racionalcrítica), a la que espolea exactamente igual el si que el no.

"La diferencia entre Einstein y una ameba, aunque ambos empleen el método de ensayo y supresión de errores, estriba en que a la ameba le desagrada equivocarse, mientras que a Einstein le intriga: busca errores conscientemente y desea aprender descubriéndolos y suprimiéndolos. El método de la ciencia es el método crítico" ${ }^{8}$.

El error consciente enseña igual que la verdad. A los niveles racionales críticos de la evolución cultural el error ya no mata como sí lo hace a otros niveles evolutivos.

\section{Realismo frente a idealismo}

Esta epistemología evolucionista, que sitúa el conocimiento en el «amplio y apasionante contexto de la evolución biológica» (MP 58), pone de relieve

7 SBW 32, 31. Respecto al conocimiento innato, una defensa suya eficaz contra el conductismo es la de Konrad LoRENZ, Evolución y modificación de conducta, Siglo XXI, México 1971, 105ss.

8 CO 74; MP 91, 71. La actitud crítica, «salvajemente especulativa» de Einstein, no sólo la enfrenta Popper a la de la ameba encadenada a un nicho biológico mínimo, sino también a las veleidades de los hados divinos en que creía, por ejemplo, otro colega genial, Max BORN (CO 173). 
con mayor crudeza el error fundamental de la epistemología clásica de la creencia: pensar que el carácer claro, distinto e inmediato de nuestras impresiones, percepciones o ideas es como el sello divino de su verdad (o falsedad), es decir, creer que ese carácter la determina o es su criterio. Frente a ello Popper opone tres cosas fruto de su realismo científico ${ }^{9}$ : (1) Nunca podemos sentirnos justificados o autorizados a pretender que una teoría sea verdadera alegando su inmediatez y claridad, porque la inmediatez y claridad son resultado ya del hecho biológico de que una teoría sea verdadera, es decir, del hecho de que nuestro aparato mental esté bien adaptado al medio en ese caso y por tanto al nivel de complejidad de la teoría. (2) Si hay alguna justificación de la validez de esa verdad-adaptación o interrelación con el medio es simplemente el hecho de que se sobrevive por ella.

«Podemos decir que nuestras creencias más prácticas están próximas a la verdad en la medida en que sobrevivimos. Así se erigen en la parte más dogmática del sentido común que, aunque no sea en absoluto fiable, verdadero o cierto, constituye siempre un buen punto de partida" ${ }^{10}$.

(3) No sólo buscamos éxito biológico o instrumental: «en la ciencia buscamos la verdad" (CO 73). En la ciencia y en todo conocimiento objetivo. Y la verdad, a otros niveles que los del mundo uno, biológico y evolucionista duro, donde el precio del despiste es la muerte, sigue otro tipo de evolución no vio-

9 Si por realismo se entiende fundamentalmente, como hay que hacer en este caso, realismo científico (frente a la metafísica), quizá sea oportuno aclarar en este punto que a pesar de las apariencias, es decir, de sus cantos y loas a la ciencia (el último más efusivo en MP 20-21, por ej.), Popper, como él mismo confesó a menudo (en SBW 16, por ej.), no fue un cientificista a ultranza. En efecto, cree que en principio hay ya que distinguir "tajantemente» las cuestiones metacientíficas de verdad o validez —incluso la de la justificación de la preferencia de una teoría a otra, que es el único tipo de "justificación" que Popper cree posible: el de la preferencia racional- de las cuestiones genéticas, históricas o psicológicas, estrictamente científicas. Y ya en la LIC llegaba a la conclusión de que los epistemólogos como él podían reclamar precedencia sobre los genetistas porque las investigaciones lógicas sobre la verdad y validez de las teorías pueden ser y son de la mayor importancia para las investigaciones genéticas, históricas e incluso psicológicas. Y, en todo caso, anteriores. "Hablo, pues, de epistemología evolucionista, aunque sostengo que las ideas fundamentales en epistemología no son de carácter fáctico, sino lógico. A pesar de ello, todos sus ejemplos y la mayoría de sus problemas pueden ser sugeridos por estudios sobre la génesis del conocimienton (CO 71-72).

$10 \mathrm{CO} 72$. El conocimiento permanece siempre hipotético o conjetural precisamente porque nuestra adaptación al medio siempre presenta, en definitiva, una realización imperfecta (MP 85; 20, 21). 
lenta, del mundo tres, cuya lógica interaccionista de progreso es semejante, sin embargo, a la evolución de "uñas y dientes", aunque aquí se hará ya por medio del lenguaje descriptivo y argumentativo y de la crítica racional. El precio del despiste en ella no es, en último extremo, más que la muerte de la teoría: normalmente con su crítica ya es bastante. Más allá de los niveles expresivos y comunicativos anteriores, del mundo uno o del mundo dos, que el hombre comparte básicamente con el animal, el lenguaje descriptivo y argumentativo permite la formulación lingüística (hablada o, mejor, escrita o, mucho mejor, impresa: todo sea en pro de la objetividad) de teorías, cosa que a su vez permite criticarlas.

\section{Dos tipos de evolución}

Como estamos viendo, en esta epistemología evolucionista se conjugan dos tipos y dos sentidos de evolución en el aumento de conocimiento. Desde el punto de vista crítico, Popper veía mal desde su juventud ${ }^{1 t}$ que la teoría de

1 El origen del interés de Popper por la teoría de la evolución proviene del influjo de Boltzmann y Mach, que todavía en vida de Darwin introdujeron sus ideas en Viena. Debido a los brutales cortes que tuvo que sufrir su primer manuscrito para ver la publicación en la forma en que lo conocemos (LIC) no se nota hasta qué punto la teoría del conocimiento popperiana era evolucionista ya desde el principio. Pero lo era. (El origen de todo ello -y el origen de su peculiar escepticismo- fue la decepción que el joven Popper se llevó en 1919 cuando Eddington demostrara definitivamente la superioridad de la teoría de Einstein sobre la de Newton, tenida por cierta y absoluta durante más de dos siglos. Si las verdades consideradas intocables cambian, con ello quedaba claro que había que incrustrar evolución en la teoría de la ciencia kantiana - Kant fue el primer impulso de Popper a filosofar- y en la teoría del conocimiento en general: las verdades no podían ser definitivas, ni las certezas, absolutas. Las teorias habian de ser cambiantes y, por tanto, siempre conjeturales, siquiera para no hacer el ridículo.) De todos modos hay que decir, a propósito, que el evolucionismo de Popper, efectivamente, como él mismo recalca, es original con respecto a otros evolucionistas vieneses del conocimiento (Lorenz, Riedl) que tuvieron su misma formación e influjos. Cfr. P. Markd, "Evolutionäre Erkenntnistheorie bei Karl. R. Popper», o. c., 40. Esa originalidad se cifra en dos aspectos claves en la epistemología popperiana, en general, en los que se basa a su vez, como vemos y veremos, el escepticismo blando que la tiñe. Estos son: (1) la inducción no desempeña papel alguno en el establecimiento de hipótesis; (2) según el origen todo conocimiento es a priori. Inducción y apriori (Hume y Kant) son los dos grandes temas de base de la epistemología popperiana desde el comienzo - la base de su pregonada objetividad-, que recoge también perfectamente la teoría posterior del mundo tres.

Popper mismo se encarga a menudo, como insinuábamos, de recordar y enfatizar la "total diferencia" de su teoría evolucionista del conocimiento con todas las demás, sean vienesas o no 
Darwin no tuviera concurrentes, cosa rara en la ciencia; por eso, probablemente, distinguió dos interpretaciones, al menos, de la teoría de la selección: la dominante, pasiva y pesimista, y la suya propia, activa y optimista, como su propio escepticismo. Esto matiza los dos tipos de evolución de que venimos hablando: uno cruel, que no rebasa el nicho biológico animal, en el que el error se paga con la muerte, y otro no violento, racional, típicamente humano, en el que el error no lleva más que a la discusión crítica y a la desaparición de las teorías, no de quien las sustenta ${ }^{12}$. Activa/pasiva, violenta/no violenta, empírica/lógica, biológica/crítica: en estas categorías hay que juzgar la evolución en el pensamiento de Popper. Y en el marco que describen la cuestión cognoscitiva del aumento del conocimiento se plantea como debe: comienza a nivel biológico, como sabemos, por el hecho homológico de que los animales también conocen, hasta que alcanza cotas evolutivas culturales no violentas, simplemente críticas, racional-críticas. Con ellas se inicia la historia del mundo tres y entonces es difícil exagerar ya con respecto a la importancia de los efectos de retroalimentación que la evolución típica de ese mundo - la evolución racional, cultural, crítica, lógica, no violenta- produce sobre nosotros: sobre nuestros cerebros, tradiciones, disposiciones a la acción (creencias) y acciones mismas ${ }^{13}$. La función argumentadora del len-

(cfr. por ej. EPEE 32). Yo veo la presunción intelectual de Popper, en este punto y en muchos otros, muy cercana a la que suele acompanar en general al pathos ilustrado que Wellmer, por ejemplo, atribuye siempre a su racionalismo crítico (cfr. A. Wellmer, Methodologie als Erkenntnistheorie. Zur Wissenschaftslehre Karl R. Poppers, Suhrkamp, Frankfurt, 1967, 8). Y más bien se trata de una vanidad inofensiva e ingenua, un tanto pequeñoburguesa, como la de cualquier scholar engolado. Por otra parte más comprensible en él, ensombrecido siempre por la sombra genial de su paisano Wittgenstein.

12 En el darwinismo habría así, en el mismo sentido en que hablábamos antes del realismo científico popperiano, elementos empíricos y no empíricos: el éxito, la sutileza y complejidad del ajuste al medio y de los cambios paralelos de los organismos, que llevan por ejemplo a la superación del organismo y del medio en el mundo tres, hablan de que el método de ensayo/error, por el que básicamente tiene lugar este proceso acrecentativo, no es simplemente empírico sino que pertenece a una "lógica de la situación" - la lógica del "conocimiento básico" o del "trasfondo" que hemos visto- en la que se inserta y desde la que se pergeña su estrategia. Con esta base lógica de la evolución "la epistemología evolucionista nos permite comprender mejor tanto la evolución como la epistemología en la medida que ambas coinciden con el método cientffico", es decir, objetivo, crítico racional, lógico lingüístico, etc., y no sólo empírico (CO 73).

13 La epistemología tradicional de la creencia, que se interesa por el mundo dos psicológico, por el conocimiento como un tipo particular de creencia cierta basada en la inmediatez de la percepción y así justificable, no podría explicar, en este sentido, que los filósofos o los científicos critiquen entre sí sus teorías, destruyéndolas por la crítica y preferencia racionales, y no perezcan ellos - como tales- sin embargo en el intento. 
guaje en el mundo tres convierte a la crítica racional en el instrumento fundamental del desarrollo ulterior del conocimiento objetivo.

El esquema popperiano «P1 $\rightarrow \mathrm{TT} \rightarrow \mathrm{EE} \rightarrow \mathrm{P} 2$ " describe a grandes trazos esa historia. Es «el esquema del aumento de conocimiento mediante la supresión de errores en virtud de la crítica racional sistemática... el esquema de la búsqueda de la verdad y contenido mediante la discusión racional. Describe el modo en que salimos de nuestros cepos. Suministra una descripción racional de la emergencia evolutiva y de nuestra auto-trascendencia por medio de selección y critica racional. ${ }^{14}$. Es el esquema de la teoría del conocimiento como teoría del aumento de conocimiento. (Ahora se ve mejor que el conocimiento y su aumento van esencialmente unidos.) La dialéctica peculiar de este esquema constituye también el corazón del escepticismo popperiano: crítica y discusión racional sistemática, preferencia racional fundada en ella, búsqueda perenne de la verdad, nada más que verosímil siempre. La dialéctica de un conocimiento conjetural, crítico, polémico, preferidor racional, en búsqueda perenne de la verdad (he ahí su aumento esencial), consciente de la infinitud del camino pero animoso en andarlo porque, entre otras cosas, no hay otro camino (sino la pendiente al dogmatismo e intolerancia) ni otro modo de hacer camino hacia una humanidad y un mundo abiertos, libres y en constante evolución hacia formas nuevas de libertad y apertura.

\section{Verdad y verosimilitud}

Por todo lo que sólo hemos insinuado, el conocimiento objetivo popperiano - «sin conocedor», «sin sujeto cognoscente" (CO 111) - no posee, ni

$14 \mathrm{CO} 119 . \mathrm{El}$ esquema significa: partimos de un problema (P1), procedemos a tantear una solución estableciendo para ello una teoría tentativa (TT), sometemos tal teoría al proceso de eliminación de errores (EE) en una discusión racional crítica y en contrastaciones experimentales, de modo que surja de todo ello un nuevo problema (P2), que se verá envuelto inmediatamente en el mismo proceso contrastador. P2 será una nueva formulación evolucionada de P1, que quedará total o parcialmente superado en él. En el caso raro de una superación total de la contrastación, la "situación problemática" - al menos- sí habrá evolucionado. Ni los nuevos problemas ni las nuevas situaciones problemáticas (el contexto histórico-cultural, lógico en el mundo tres, del problema) las creamos, en general, voluntariamente sino que emergen del campo de esas nuevas relaciones que no podemos dejar de engendrar con cada acción del mundo tres por poco que lo pretendamos. (Cfr. CO 225, 261, etc.) Para las amplísimas posibilidades de este esquema, cfr. I. REGUERA, El tercer mundo popperiano, o. c., 141-147. 
puede poseer, ninguna de aquellas aspiraciones subjetivas - creencia, certeza, verdad, fundamento, etc.- de la tradición; por su contenido lógico esencial del mundo tres consiste fundamentalmente en teorías hipotéticas, conjeturas, suposiciones, problemas, «situaciones problemáticas», discusiones y preferencias racionales; aunque nunca olvide su condición biológica, sujeta a los apriorismos cognitivos básicos de cualquier animal, se trata de un conocimiento humano por antonomasia en ese sentido, que consta de expectativas formuladas ya en un lenguaje avanzado y sujetas por tanto a discusión crítica (si no estuviera formulado en instancias objetivas del mundo tres no sería criticable); y que aumenta y cambia por esa crítica, a la que debe no sólo su carácter permanentemente hipotético, sino también su objetividad. La criticabilidad es el criterio de objetividad: la crítica permanente vela por la intersubjetividad del conocimiento; su carácter siempre conjetural, siempre verosímil es el mejor síntoma de ella, de que nadie ni nada se apropia de la verdad cerrando el mundo a otras formas... Si al principio decíamos que el escepticismo de Popper coincide con su lucha contra el subjetivismo por la objetividad del conocimiento, ahora podemos decir más: el escepticismo popperiano coincide con la conciencia de la criticabilidad permanente del conocimiento. Esta característica proviene en esencia del hecho de que el objetivo del conocimiento, tanto del biológico como del cultural, nunca se alcanza plenamente: nuestra adaptación al medio siempre es imperfecta (MP 85). Desde este punto de vista resulta hasta grotesca la pretensión tradicional de verdad y certeza absolutas y adquieren su relieve definitivo los caracteres del escepticismo popperiano.

\section{Preferencia racional frente a verdad}

"El conocimiento científico, el saber científico es siempre hipotético: es un saber de presunción. Y el método del conocimiento científico es el método crítico: el método de la búsqueda y eliminación de fallos al servicio de la búsqueda de la verdad" (SBW 13).

Es lo que repite Popper una y otra vez, esta secuencia: conocimiento objetivo $\rightarrow$ conocimiento conjetural $\rightarrow$ conocimiento crítico $\rightarrow$ conocimiento búsqueda de la verdad. "El método de la ciencia es el método de conjeturas audaces e ingeniosas seguidas por intentos rigurosos de refutarlas" (CO 83). Una conjetura es una teoría y una conjetura audaz es una teoría de mucho peso o de gran contenido. Teorización audaz más exposición a pruebas severas: ése, 
que es el método de la ciencia, no es otra cosa también que el método de la vida misma (MP 21). (El método de la ciencia o del conocimiento objetivo es el método de la supervivencia.) La audacia y el ingenio están ligados al contenido descriptivo o explicativo de una conjetura; y éste, a su "contenido de verdad" que, en cualquier caso, ha de ser mayor que el de su predecesora si quiere substituirla. Pero no basta eso ya que nunca podemos estar ciertos absolutamente de la verdad de una teoría y por tanto de su valía.

"Lo único que podemos hacer es buscar el contenido de falsedad de nuestra mejor teoría, cosa que llevamos a cabo intentando refutarla; es decir, intentando contrastarla de un modo riguroso a la luz de todos nuestros conocimientos objetivos y de todo nuestro ingenio... Pues si sale airosa de todas estas contrastaciones, podemos tener buenas razones para suponer que nuestra teoria, que, como sabemos, posee un contenido de verdad superior al de su predecesora, puede que no posea un contenido de falsedad mayor. Además, si no logramos refutar la nueva teoría, especialmente en los dominios en que su predecesora ha sido refutada, entonces podemos tomar esto como una de las razones objetivas en favor de la conjetura de que la nueva teoria constituye una aproximación a la verdad mejor que la vieja" (CO 83).

Así funciona la marcha real del conocimiento... La contrastación de las teorías científicas forma parte, pues, de su discusión crítica o racional. (Es en este contexto donde Popper encuentra que "crítico" es el mejor sinónimo para «racional».) Esta discusión crítica o racional nunca puede justificar ni fundar racionalmente nuestras pretensiones de conocimiento cierto porque nunca puede aportar razones suficientes para decir de una teoría que es verdadera. Popper ve perfectamente el lado nihilista (antifundacionalista) posmoderno de toda teoría del conocimiento pero se salva de él aceptando los mínimos que recoge su racionalismo crítico... Con ingenio y suerte la discusión crítica sí puede establecer razones suficientes para que en un momento histórico concreto y a un nivel de discusión concreto como los del presente una teoría audaz y discutida crítica, exhaustiva, rigurosa e ingeniosamente pueda considerarse como la preferible o la "mejor" racionalmente, o sea, como la de mayor contenido, la más potente, la mejor contrastada, en una palabra la más cercana a la verdad, la que supone una aproximación mayor a un ideal inalcanzable y sabido así, la más verosímil de las teorías rivales expuestas hasta ese momento. Esta especie de historicismo es esencial al racionalismo crítico popperiano. 
"Nunca podemos justificar racionalmente una teoría - es decir, la pretensión de que conocemos su verdad- pero si tenemos suerte podemos justificar racionalmente la preferencia provisional de una teoría sobre todo un conjunto de teorías rivales; es decir, respecto al estado actual de la discusión» (CO 84).

El preferidor racional es el profeta de la certeza frustrado. Todavía hay en Popper un optimismo racional conmovedor que comparte de modo natural con su escepticismo (dinámico y esperanzado): un evidente pathos ilustrado, como hemos dicho, cuyos demonios le impiden abandonarse a la desesperanza. El progreso todavía es posible, si no ya por la razón sin más, digamos, sí por la razón crítica. La ciencia es el modelo - aunque no tiene la exclusiva- de ese progreso/aumento del conocimiento mediante crítica e ingenio. El modo en que Popper sublima sus desesperanzas es esa modalidad racional crítica de arrojo, ingenio y fortuna que proclama para el pensar. $Y$ es lo que proporciona indudable gracia también a su propio pensamiento, aunque en las medidas - más que prudentes, tibias - que aprendió no tanto de su Viena natal cuanto de las maneras oportunas del ingenioso académico anglosajón de turno, que admiraba.

\section{Búsqueda de la verdad frente a verdad}

La verdad objetiva, por lo que ya sabemos, no existe objetiva y absolutamente en sí, pero sí como objetivo último regulador, que hace que su propia búsqueda proceda de algún modo a priori; ignorar esto es entregarse en manos del relativismo cultural que menosprecia los ideales del ser racional humano, dice Popper.

"La tarea de todos nosotros como seres humanos pensantes es el descubrimiento de la verdad. La verdad es absoluta y objetiva, sólo que no la tenemos en el bolsillo. Es algo que buscamos continuamente pero que a menudo sólo difícilmente encontramos; y continuamente intentamos mejorar nuestro acercamiento a la verdad. Si la verdad no fuera absoluta y objetiva no nos podríamos equivocar. O nuestros errores serían igual que nuestra verdad... Nuestra búsqueda de la verdad procede siempre así: inventamos - a priori- nuestras teorías, nuestras generalizaciones... Sólo tenemos que ver con conjeturas o hipótesis... creadas por nosotros. Constantemente intentamos confrontar esas conjeturas de algún modo con la realidad y al 
mismo tiempo mejorarlas y acercarlas a la realidad». Dicho de otra manera: «Nuestra principal tarea filosófica y científica debe ser la búsqueda de la verdad. La justificación no es un objetivo, mientras que la brillantez y habilidad como tales son una pesadez. Deberíamos intentar ver o descubrir los problemas más urgentes tratando de resolverlos proponiendo teorías verdaderas... o, en cualquier caso, proponiendo teorías que se acerquen más a la verdad que las de nuestros predecesores» ${ }^{15}$.

En este tema grave y ambiguo - por sus connotaciones de todo tipo-, muchas veces desorbitado - en cualquiera de sus sentidos - de la verdad o de su búsqueda Popper recomienda sencillez, claridad, brevedad y evitar complicaciones y tecnicismos innecesarios. Cree que hacer esto es un deber moral del intelectual. El conocimiento que busca la verdad ostenta tonalidades morales inconfundibles ${ }^{16}$. Pero aunque Popper tiene de sobra clara, como sabemos, la diferencia entre los matices objetivos y subjetivos del conocimiento, que en este caso se concretaría - ya desde los estoicos - en la distinción neta y obligada entre verdad y veracidad, esa tonalidad moral que nos ocupa no tiene nada que ver con eso en principio, sino con las propias calidades técnicas del conocimiento objetivo, que le obligan técnicamente al realismo antimetafísico: a buscar la verdad sin paliativos, subterfugios ni relativismo alguno. La verdad es correspondencia con la realidad. Los utilitarismos, pragmatismos, consensualismos, sociologismos en su definición no son más que componendas (inter)subjetivistas. Todo aquel que ha hecho alguna vez de jurado en un juicio, dice Popper, sabe bien que no importa para nada la convicción subjetiva sino la atenencia a los hechos. Menos importaría aún el consenso...

\section{Verdad objetiva frente a verdad cierta)}

Cuando Popper habla de la (teoría de la) verdad se refiere a la verdad objetiva, que él entiende desde la teoría del sentido común (correspondencia con

15 EPEE 36-37; CO 51. En la última cita queda explícito, al menos, que, en cuanto búsqueda de la verdad, el conocimiento científico y el filosófico coinciden.

16 En este asunto «la falta de claridad es un pecado y la presunción, un crimen» (CO 51). Y el relativismo filosófico al respecto, "una traición a la razón y a la humanidad" (SBW 14). Claro que para Popper la verdad es casi el único - y, desde luego, el primer y supremo- valor moral en el que cree. Sea como sea, resultan impactantes sus repetidas y solemnes declaraciones al respecto... 
los hechos o con la realidad), como decimos, pero depurada por los análisis semánticos (sin semántica) de Tarski, quien en $1935^{17}$ le explicó personalmente su teoría de la verdad sentados ambos en un «inolvidable banco" del Volksgarten vienés. Popper rechaza cualquier otro concepto de verdad como relativismo intelectual irresponsable, sabemos. Una de sus últimas formulaciones de la verdad a ese estilo y precisamente en este contexto del conocimiento es ésta: «una teoría o proposición es verdadera cuando el estado de cosas descrito por ella corresponde con la realidad" (SBW 13). Es equivocado, por el contrario, equiparar verdad y certeza, verdad y verdad cierta. (Todo lo que hemos dicho del conocimiento hasta ahora lo corrobora.) Esto es lo que Popper quiere dejar y deja siempre bien claro:

"Gracias a la obra de Tarski la idea de verdad objetiva o absoluta - esto es, de la verdad como correspondencia con los hechos- parece ser aceptada con confianza en la actualidad por todos los que la comprenden. Las dificultades para comprenderla parecen tener dos fuentes: primero, la combinación de una idea intuitiva sumamente simple con un cierto grado de complejidad en la ejecución del programa técnico al que da origen; segundo, el dogma difundido pero equivocado de que una teoria satisfactoria de la verdad debe ser una teoría de la creencia verdadera, de la creencia bien fundada o racional. En realidad, las tres rivales de la teoría de la correspondencia a saber, la teoría de la coherencia que confunde la consistencia con la verdad, la teoría de la evidencia que confunde "verdadero" con "conocido como verdadero" y la teoría pragmatista o instrumentalista que confunde la utilidad con la verdad - son todas ellas teorías de la verdad subjetivas (o "epistémicas"), en contraposición con la teoría objetiva (o "metalógica") de Tarski. Son subjetivas en el sentido de que todas ellas parten de la posición subjetivista fundamental que sólo puede concebir el conocimiento como un tipo especial de estado mental, o como una disposición, o como un tipo especial de creencia caracterizada, por ejemplo, por su historia o por su relación con otras creencias” ${ }^{18}$.

La verdad es correspondencia con los hechos o con la realidad, pues. Mejor formulado: una teoría es verdadera si, y sólo si, corresponde a los hechos.

17 El mismo año en que publica su famoso artículo en alemán: "Der Wahrheitsbegriff in den formalisierten Sprachen", Studia philosophica I, 1935, 261-405. Cfr. CO 291.

18 C\&R 260-261. Cfr. en gral. Idem 258 ss., CO 288 ss. 
Mejor aún: la expresión $\mathrm{P}$ del lenguaje objeto es un enunciado que corresponde a los hechos si, y sólo si, p (donde p sería una descripción metalingüística del estado de cosas al que se refiere $\mathrm{P}$ ). Desde Tarski es obvio que si queremos hablar de la verdad - de la correspondencia entre un enunciado y un hechohemos de hacerlo metalingüísticamente: sólo así, entre otras cosas, pueden evitarse las llamadas paradojas semánticas... Se precisa para ello un metalenguaje que enuncie el hecho al que se refiere a su vez el enunciado en cuestión. Por lo tanto estamos hablando de (o definiendo) la verdad de los enunciados y hablamos de ella (o la definimos), además y sin remedio, metalingüísticamente: hablamos metalingüísticamente, diríamos, de una verdad lingüística e incluso restringida en principio a los lenguajes formalizados. (Todo sea en pro de la objetividad...) Pero también el sentido común toma otro sentido (crítico) cuando podemos así definir de modo puramente verbal su supuesto: un enunciado es verdadero si, y sólo si, corresponde a los hechos... Aparte de las incalculables ventajas teóricas inherentes a él mismo, este concepto semántico de verdad puede de algún modo ser aplicado y traducido al lenguaje ordinario. Otra cosa es que esperemos consoladores e imposibles criterios (se trata de una definición nada más) de verdad para nuestro trato diario con las cosas...

\section{No hay criterio de verdad}

Efectivamente, esta noción de verdad es objetiva pero no nos permite hablar con absoluta certeza ya que no nos suministra un criterio de verdad... Eso es lo que impide en la mayoría de los casos apreciar su relevancia. Estamos acostumbrados al espíritu burgués moderno de aferrarse a ciertas seguridades que aclaren y dirijan nuestro tentativo traficar con el medio y nos libren de la angustia del vivir incierto. Pero las cosas son de otro modo: los consuelos modernos, aún en nombre de la racionalidad, se basaban en creencias irracionales e ilusas. El progreso del conocimiento no lo rige una razón sempiterna y pura, sino una razón (mente) crítica, conjetural, evolutiva y perennemente incierta como el propio conocimiento objetivo... Más bien que suministrarnos un criterio de verdad, este concepto de verdad nos muestra que no puede haberlo. Sólo puede haberlo para lenguajes artificiales extremadamente pobres, donde prácticamente es imposible expresar algo que no sean tautologías. Si el lenguaje (el lenguaje objeto) es suficientemente rico no puede haber un criterio general de verdad. No se puede confundir, pues, el concepto con el criterio de verdad o pretender que en la pura definición se encuentre ya el criterio 
de su aplicación. Si no, no se entenderá jamás la importancia de la teoría de la verdad de Tarski, que vista desde esa perspectiva ilusa parece irrelevante. Sé lo que es la verdad, pero no sé lo que es la verdad en cada caso... La fortaleza moderna de la pretendida posesión o posesibilidad de la verdad no fue más que el bluff de una arrogancia vana, mientras que la debilidad posmoderna, digamos, de su perpetua búsqueda y multiplicación es nada menos que claridad de conciencia. ?Ah, la fortaleza de los débiles, que viven dignos en la desesperanza y el vacío sin ostentosas muecas, frente a la debilidad de los fuertes, que buscan su consuelo en certezas y fundamentos ciertos, aferrándose a esas patrañas (metarrelatos autolegitimadores o cuentos chinos) por no precipitarse al abismo! Ni siquiera hay desesperanza hoy. No puede haberla cuando los objetos de esperanza se han revelado como una mera ilusión... "No podemos pretender alcanzar una certeza absoluta: somos buscadores de la verdad, pero no sus poseedores" (CO 53).

\section{Verosimilitud frente a verdad}

La búsqueda de la verdad objetiva (absoluta y absolutista en el sentido de horizonte regulador de su búsqueda, no en el de su pretendida certeza), sin criterio general de verdad, exige al menos un criterio de aproximación a ella. Dado que nos quedamos siempre en el camino a la verdad, que es además el camino arduo y complicado del aumento de conocimiento y que no lleva a certeza alguna ni con certeza a ninguna parte, hemos de poder dar razones al menos —o al menos en algunos casos más claros- de esa pretensión intuitiva -que nos guía un poco a ciegas, inconscientemente o a priori, decíamosde que haciendo tal y tal cosa - sobre todo en el mundo tres- nos acercamos a la verdad más que haciendo tal y tal otra, por ejemplo (CO 301, C\&R 269). Porque, en efecto, ?cómo sabemos, si no hay un criterio general de verdad, que una teoría ha superado a otra porque se acerca más a la verdad que ella? La idea que gobierna (un tanto) este camino de búsqueda de la verdad es la de (mayor o menor) acercamiento o proximidad a ella. Esta idea es la «verosimilitud»: la de mayor o menor verosimilitud... La verdad, en efecto, no es la única propiedad importante de nuestras teorías. En el camino a la verdad hay muchas cosas relevantes para el conocimiento objetivo que no poseen su marchamo absoluto. Son las más, como sabemos, porque, aparte de las demostraciones válidas y simples de certeza absoluta del mundo tres (el "conocimiento demostrable", 
que llama Popper), que comprenden (si comprenden algo) las proposiciones tautológicas de la lógica formal y de la aritmética finita, y aparte de triviliadidades y tautologías materiales como que todas las mesas son mesas, por ejemplo, el conocimiento objetivo es conjetural, hipotético, evolutivo, etc. Buscar la verdad absoluta y absolutamente cierta es en el fondo un empobrecimiento si por culpa de ello se desprecian las verdades fragmentarias, conjeturales, imperfectas (respecto sólo a ese vano patrón absoluto), que pueden solucionar los problemas reales, concretos, urgentes e interesantes. Los valores de verdad son múltiples y variados; no hay un valor único (no hay un criterio), todos valen aunque ninguno valga todo, y cada uno puede contribuir a solucionar un problema: tampoco los problemas son un único y absoluto problema, sino muchos y dispares como sus soluciones. Como la vida misma.

Así como muchos filósofos sospechaban de la idea intuitiva de verdad hasta que Tarski dio una noción lógica de ella, Popper pretende por idénticos motivos hacer lo mismo con la idea intuitiva de verosimilitud. Popper se esfuerza en mostrar que la verosimilitud se puede definir o reducir a otros términos: contenido de verdad, contenido de falsedad y en último extremo probabilidad lógica (CO 63, 99-100). Pero no pretende una exactitud y aplicabilidad estrictas, es decir, no pretende encontrar una función numérica aplicable a teorías, que nos dijese en términos numéricos cuál es su grado de verosimilitud o al menos de corroboración o la cuantía de su contenido de verdad. Pretende "rehabilitar una idea de sentido común que necesito para describir las metas de la ciencia y que subyace como principio regulador (aunque sólo sea de modo inconsciente e intuitivo) a la racionalidad de toda discusión crítica" (CO 64; 54; cfr. 58ss.). En este sentido podemos identificar la idea intuitiva de verosimilitud (aproximación a la verdad) con la idea lógica (funcional) de elevado contenido de verdad (y bajo contenido de falsedad). En ambas hay gradación y en ambas la validez (verdad) es paralela a la gradación (contenido). Cantidad de verdad (contenido) que constituye también la calidad suya (aproximación): la verosimilitud. Pero lo importante no es ninguna calidad psicológica del espíritu, sino la cantidad, la extensión de la clase T (la clase de enunciados verdaderos que se siguen de una teoría), el dominio de una función, no una esencia variable cualitativa por la cual cualquier caso concreto es igualmente (esencialmente) verdadero por más que su campo de variabilidad sea más o menos grande. La verdad es un concepto general aristotélico, digamos, fundamentalmente extenso (función), no una idea platónica, fundamentalmente intensa (variable). Una teoría es más o menos vero- 
símil, más o menos cercana o semejante a la verdad que otra «si, y sólo si, se siguen de ella más enunciados verdaderos pero no más enunciados falsos, o, al menos, igual cantidad de enunciados verdaderos y menos enunciados falsos» (CO 58, C\&R 271). La teoría de mayor contenido de verdad, es decir, de mayor cantidad de enunciados verdaderos implicados lógicamente por ella, sería la más verosímil. La verosimilitud de un enunciado es una variable dependiente de su contenido lógico de verdad (la clase T). «Esta afirmación constituye la base lógica del método de la ciencia: el método de conjeturas audaces seguidas de intentos de refutación» (CO 59; MP 21)... La relatividad de la verdad absoluta se ha hecho tan esencial a la verdad que de una falsedad pueden seguirse verdades, que una falsedad puede ser incluso verdad y hasta la mejor verdad posible en un momento concreto: todo depende del tamaño de su clase consecuente $T$ (o contenido lógico suyo). Muchas hipótesis de la teoría de Newton, por ejemplo, aunque ésta fuera falsa (como probablemente lo sea), son una aproximación a la verdad mucho mejor, por ejemplo, que la verdad analítica de que dos más dos son igual a cuatro, porque este enunciado suministra poco contenido de verdad y aquella teoría, por la tremenda cantidad de consecuencias verdaderas interesantes e informativas que contiene, posee un contenido de verdad muy grande (CO 60-61).

¿Qué puede significar verosimilitud desde esta perspectiva? Un aferrarse desesperado a las pavesas tambaleantes de la razón. (Ya hemos insistido, con Wellmer, en que Popper nunca perdió su pathos ilustrado...) Esta idea de verosimilitud (de verdad), en efecto, define perfectamente el optimismo a la baja, el optimismo escéptico (escepticismo dinámico y esperanzado) del racionalismo crítico popperiano. Buscar la verdad sólo puede representar un objetivo satisfactorio si, a parte de aceptar ya una idea alambicada de verdad como la de Tarski y supuesta ella, aceptamos también en nuestra investigación enunciados falsos con tal de que no sean demasiado falsos... El refrendo lógico de la verosimilitud permite hablar todavía de verdad aunque no sabe uno muy bien para qué, porque el concepto de verosimilitud la ha engullido totalmente por más que se fundara al comienzo en ella. Pero para Popper, a pesar de todo: «la búsqueda de verosimilitud es una meta más clara y realista que la búsqueda de verdad» ( $\mathrm{CO}$ 63). La búsqueda de la verdad será búsqueda de verosimilitud, quedando la verdad de verdad superada en ella. La verdad es verosimilitud y ésta, búsqueda de nada. Búsqueda de una verdad objetiva y absoluta apriórica sin contenido alguno, mero ideal regulador de su propia búsqueda como proceso racional crítico de aumento del conoci- 
miento superando todo relativismo cultural, como hemos visto ${ }^{19}$. (¿Qué realidad ha de corresponder a ese vacío? Una realidad siempre abierta, en efecto.) Una búsqueda sin más de sí misma. (La verdad es la buisqueda de la verdad: toda una vida teórica — vida mundo tres-dedicada a ella. La filosofia es, en ese sentido, filosofar. El pensamiento, pensar. Lo importante es pensar, no lo que se piensa... No hay otro valor teórico en realidad que la propia buisqueda o aumento del conocimiento. La verdad puntual es vanal por efimera. La salvación no está en ningún dogma sino en la vida —el vivir- del conocimiento. El «enamoramiento" popperiano por el pensar...) Una búsqueda sin más, que se autorregula (a priori) a sí misma a lo largo de la evolución del conocimiento por los complejos mecanismos de interacción de los mundos. El propio aumento del conocimiento y su evolución. La vida misma. La supervivencia de la vida orgánica y de la vida racional, onto y filogenéticamente. Para eso pensamos, conocemos. En definitiva el mismo vivir humano es conocer. Las mismas leyes rigen el conocimiento y la supervivencia. Es bonito estudiar la vida llamándola conocimiento ${ }^{20}$... Pero acabamos de decir que es lo mismo. Sobre todo en la fábula del tercer mundo.

\section{Escepticismo dinamico y esperanzado-esperanzador}

Conocimiento objetivo, conjetural, crítico, buscador de la verdad; la búsqueda de la verdad no es sino búsqueda de verosimilitud y en el fondo, de nada... Todas las características vistas en Popper respecto al conocimiento y a la verdad pergeñan en él un talante intelectual que él mismo calificó, como venimos repitiendo, de escepticismo dinámico, esperanzado o esperanzador. Popper es y no es escéptico. Un realista escéptico sería una cosa rara, como dice él mismo. Y eso es Popper en este sentido: un escéptico raro, que lo es y no lo es, como decimos. Además de por sus creencias realistas, Popper no es escéptico por otras dos razones dispares. Primero, por una razón moral que no viene tanto al caso: porque tiene algunas creencias morales (en la verdad

19 Si a pesar de esta su vaciedad definitiva la verdad se entiende como correspondencia criticando todos sus demás conceptos como relativismos infames, como hace Popper, no resulta extraña la crítica de Habermas a esta postura como “ilusión objetivista" (J. HABERMAS \& N. LuHManN, Theorie der Gesellschaft oder Sozialtechnologie, Suhrkamp, Frankfurt, 1971, 237).

20 Un bello libro sobre el tema: H. KEUTH, Realität und Wahrheit. Zur Kritik des kritischen Rationalismus, Mohr, Tübingen, 1978. 
objetiva como valor moral, en la crueldad como no-valor moral, en la realidad e importancia de la esperanza y la bondad humanas, etc.) que le elevan por encima de un positivismo ramplón. Segundo, por una razón epistemológica -ésta sí fundamental— que proviene del hecho de que como filósofo no se interesa por la duda ni por ningún otro aspecto subjetivo del conocimiento: "Lo que me interesa son los motivos objetivos crítico-racionales por los que una teoría es preferible a otra en la buisqueda de la verdad" (SBW 16; 15). Pero sí es escéptico -en algún sentido- porque niega la posibilidad de un criterio general de verdad que no sea simplemente lógico-tautológica y con ello asimila al conocimiento todas las categorías relativas que hemos visto. Este escepticismo - y en ese sentido- que tine su teoría del conocimiento y de la verdad lleva desde el principio la impronta de sus dos amores y desamores intelectuales con Hume y con Kant. Nunca mejor que en el diálogo con ellos se entiende este peculiar tono escéptico de la epistemología del racionalismo crítico.

A costa de la reducción racional que sea Popper intentará aminorar el desengaño con respecto a las excelencias modernas de la razón producido por la respuesta de Hume al problema inductivo. Una respuesta paradójica que destruyó a la vez el empirismo y el racionalismo. Negativa lógicamente: la inducción no tiene validez lógica porque ningún argumento lógico apoya la validez (básica en el empirismo) de una inferencia general hecha a partir de enunciados relativos al pasado. Positiva psicológicamente: actuamos basándonos en un mecanismo psicológico de asociación que nos fuerza a creer por hábito o costumbre que ocurrirá en el futuro lo que ha acurrido en el pasado, es decir, el mecanismo fundamental de nuestra mente por el que vivimos y actuamos es la asociación reforzada por la repetición. No vivimos ni actuamos, pues, por razones elevadísimas... Este irracionalismo que descubrió Hume en el seno de la racionalidad humana, esta amenaza de regresión infinita por el agujero de la inducción —que destruía, por ejemplo, la firmeza racional de los fundamentos mismos de la mecánica newtoniana reduciéndolos en definitiva a costumbre o hábito- alarmó a Kant, le resultó inaceptable y lo llevó a creer que podía superarse en el caso de que hubiese y fuese posible establecer un principio de inducción — de causalidad - válido a priori que fundase la validez apriórica de ciertos enunciados sintéticos (gran parte de la física newtoniana). Esa fue la base de su esfuerzo filosófico. Pero todo esto se vino abajo (dramáticamente para el joven Popper) al descubrirse que la mecánica newtoniana no era válida a priori, sino una conjetura, una «hipótesis maravillosa» 
pero nada más ${ }^{21}$. El dramatismo de esta conciencia no fue exclusivo del joven Popper. Según Russell, es también el responsable de la esquizofrenia del hombre moderno, por cuanto puso de relieve crudamente el irracionalismo de base que mina la razb́n o, mejor dicho, sus ilusiones modernas. Un irracionalismo de base que deja en el vacío no sólo todas las pretensiones fundantes tradicionales de la razón, sino su propio sentido. Según las conclusiones de Hume, en efecto, «ni siquiera nuestro intelecto funciona racionalmente. El hábito, racionalmente indefendible, es la fuerza fundamental que guía nuestro pensamiento y nuestras acciones" (CO 95). El hombre es producto del hábito ciego y pervive siempre manejado por él: esta evidencia fuerza al abandono del racionalismo iluso. ¿Y si esto hizo Hume, «uno de los pensadores más razonables de todos los tiempos".

Popper, más allá de Kant, aunque enfrentado a su mismo estupor, quiso haber encontrado una solución a la paradoja humeana. Esta solución - ya, o ya sólo, medio escéptica- fue la siguiente:

"No sólo razonamos racionalmente y, por tanto, de modo contrario al principio de inducción cuya invalidez fue establecida por Hume, sino que además actuamos racionalmente de acuerdo con la razón más bien que con la inducción. Actuamos basándonos no en repetición o "hábito", sino en nuestras teorías mejor contrastadas que, como hemos visto, son las que se ven apoyadas por buenas razones racionales; naturalmente, poseemos buenas razones para creer no que son verdaderas, sino que son más válidas desde el punto de vista de la búsqueda de la verdad o verosimilitud: las mejores entre las teorías rivales, las mejores aproximaciones a la verdad. Para Hume el problema fundamental era: ‘actuamos de acuerdo con la razón o no? Mi respuesta es: sí» (CO 95-96).

El acuerdo de Popper se da con una razón rebajada, medio escéptica, tal como la hemos visto en su despliegue azaroso en el proceso de aumento del conocimiento y de búsqueda de la verdad, que quizá ya no mereciera el nombre de "razón" para los modernos porque no cumpliría sus expectativas. (Y si

21 Cfr. supra, nota 10; CO 93; C\&R 112, 113, 211, 223; etc. La decepción del joven físico Popper fue triple: la caída de la mecánica newtoniana, el consiguiente desmorone de la filosofia kantiana en este aspecto y la inevitable vuelta de las amenazadoras conclusiones irracionalistas de Hume. 
no lo mereciera ¿para qué seguir con el mismo nombre que obliga a hablar de escepticismo?...) La solución de Popper no deja de ser también un tanto paradójica: no afirma la racionalidad humana plena, se limita a testificar, dice, que no hay conflicto entre la racionalidad (¿qué «racionalidad»?) y la acción práctica... En esta solución están las raíces del escepticismo moderado popperiano. Un escepticismo crítico, como su racionalidad. Moderado por la evolución y la crítica racional del conocimiento que, a pesar de la repetición y el hábito, pero también por ellos, nos proporciona "buenas" razones, razones "preferibles" y «verosímiles» para obrar. Excepto a un mínimo nivel no pensamos racionalmente desde la necesidad y validez de la lógica de la razón "pura»; más bien "actuamos" racionalmente en una evolución del conocimiento sujeta - como él- a la misma mecánica de esa praxis: al método crítico y evolutivo del ensayo/error, básicamente igual que el resto de los animales. Este racionalismo popperiano a la baja, el racionalismo crítico, sanción avispada de los mejores deseos y tópicos de la burguesía esclarecida y amante del orden de la segunda mitad de este siglo, se adorna así de los siempre interesantes tintes del escepticismo. De un escepticismo de salón, digamos, porque, en efecto, "difícilmente se podrá considerar escéptico a quien crea en la posibilidad del crecimiento ilimitado del conocimiento" (CO 99). Optimismo reformista y liberalismo siempre abierto, aplicados en este caso al conocimiento...

El escepticismo popperiano, a la baja como su racionalismo, posee, pues, los caracteres de esa crítica pretendidamente abierta y progresista de la racionalidad popperiana: esperanzado a pesar de todo y dinámico ${ }^{22}$. Este escepticismo sui generis no es más que el tono epistemológico de la racionalidad crítica.

«El punto de vista expuesto aquí apoya esperanzadoramente la posibilidad de aumento del conocimiento y, por tanto, la del conocimiento mismo. Lo único que hace es eliminar el carácter de certidumbre que el sentido común consideraba esencial para el conocimiento" (CO 99).

Así es exactamente, como hemos visto. Con sentido común más razonamiento crítico, de acuerdo con la "dialéctica" (él no cree que sea dialéctica) del esquema P1 $\rightarrow \mathrm{TT} \rightarrow \mathrm{EE} \rightarrow \mathrm{P} 2$ y de los tres mundos, Popper da contenido

22 Popper corrobora el sentido de su escepticismo, además, con consideraciones etimológicas, traduciendo «skepsis" por «investigación crítica» y consecuentemente «escepticismo dinámico» por “investigación crítica potente» o por «investigación crítica esperanzada» (CO 99). 
a su peculiar escepticismo, que también podría llamarse "filosofía crítica del sentido común" en este sentido. Su creencia y esperanza -matizadas siempre y nunca racionales - en el realismo, en el realismo científico del sentido común, le llevan a rechazar las consecuencias más duras del escepticismo humeano: la de la irracionalidad irreparable de la confianza en la existencia de cierta realidad no caótica y sobre todo la de la irracionalidad esencial de la naturaleza humana. "Por menguada que sea nuestra esperanza, tiene un fundamento totalmente racional» ${ }^{23}$. Nuestra esperanza de que las cosas no sean como no quiere Popper.

23 CO 99. Cfr. CO 100ss., 103ss. 